\title{
IMPLIKASI PENGEMBANGAN PARIWISATA BERBASIS MASYARAKAT BAGI MASYARAKAT DI DESA BONGAN
}

\author{
Putu Widya Darmayanti ${ }^{1}$, I Made Darma Oka ${ }^{2}$ \\ ${ }^{1}$ Akademi Pariwisata Denpasar, Bali \\ ${ }^{2}$ Jurusan Pariwisata, Politeknik Negeri Bali \\ E-mail: putuwidya4@gmail.com; madedarmaoka@pnb.ac.id
}

\begin{abstract}
ABSTRAK
Tujuan artikel ini untuk mengkaji implikasi pengembangan pariwisata berbasis masyarakat bagi kehidupan masyarakat di desa Bongan. Penelitian ini menggunakan data kualitatif. Pengumpulan data dilakukan dengan metode observasi, wawancara, dan studi pustaka. Informan diambil dari tokoh masyarakat yang memahami tentang implikasi pengembangan pariwisata dengan teknik snowball sampling. Data dianalisis secara deskriptif kualitatif. Hasil penelitian menunjukkan bahwa pengembangan pariwisata berbasis masyarakat mampu memberikan implikasi positif bagi kehidupan masyarakat, baik ditinjau dari dimensi ekonomi, sosial, budaya, lingkungan, maupun politik. Impliksi ekonomi, yaitu terjadi peningkatan pendapatan masyarakat; implikasi sosial, yaitu terjadinya peningkatan kualitas hidup masyarakat, implikasi budaya, yaitu melestarikan dan menghormati tradisi budaya; implikasi lingkungan, yaitu meningkatkan kesadaran dalam menjaga kebersihan lingkungan; dan implikasi politik, yaitu masyarakat mendapat prioritas dalam perekrutan tenagakerja. Dirasakannya implikasi positif tersebut mampu meningkatkan antusias masyarakat dalam mendukung pengembangan pariwisata. Diharapkan stakeholder ikut berperan aktif dalam mendukung pengembangan pariwisata baik berupa motivasi, pembinaan, manajemen pengelolaan, maupun promosi.
\end{abstract}

Kata kunci: implikasi, pariwisata, masyarakat, desa wisata

\begin{abstract}
The aims of this article to examine the implications of community-based tourism development to the life of community at Bongan Village. This research uses qualitative data. Data collection is done by observation, interview, and literature study. Informants were taken from community who understood the implications of tourism development with snowball techniques. Data were analyzed by descriptive qualitative. The results showed that the tourism development have positive implications for people's lives, both in terms of economic, social, cultural, environmental, and political dimensions. Economic implications, namely an increase the community income; social implications, namely an increase the quality of people's lives; cultural implications, namely preserve and respect cultural traditions; environmental implications, namely raising awareness in maintaining environmental hygiene; and political implications, namely the community gets priority in labor recruitment. The positive implications were increasing their enthusiasm to support the tourism development. Hoped stakeholders will play an active role to support tourism development both in form of motivation, guidance, management, and promotion.
\end{abstract}

Keywords: implications, tourism, community, tourist village 


\section{PENDAHULUAN}

Desa Bongan merupakan salah satu desa wisata di Kabupaten Tabanan dari 23 desa wisata yang telah ditetapkan menjadi desa wisata. Penetapan desa wisata ini menjadi desa wisata melalui Surat Keputusan Bupati No. 180/445/03/HK \& HAM 2018. Walaupun desa ini tergolong baru ditetapkan sebagai desa wisata tahun 2018 tetapi sudah termasuk katagori desa wisata berkembang. Kini pihak pengelola terus berbenah agar desa wisata Bongan mampu bersaing secara kompetitif dengan desa wisata lain sejenis. Pihak pengelola desa wisata terus berkoordinasi, bekerjasama dan saling bersinergi demi keberlanjutan dari desa wisata.

Atraksi wisata yang menjadi ikon desa wisata adalah peninggalan purbakala situs Kebo Iwa. Selain itu juga menawarkan keindahan alam yang masih natural dilengkapi dengan tradisi budaya yang kental menjadikan desa ini semakin menarik untuk dikunjungi wisatawan. Untuk keberlanjutan pengembangan pariwisata di desa Bongan harus memperhatikan implikasi dari pengembangan desa wisata terutama bagi kehidupan masyarakat lokal baik dikaji dari implikasi ekonomi, sosial, budaya, maupun lingkungan desa. Sutrisna (2011); Sadia (2012); Oka \& Pugra (2017); Oka \& Sumawidari (2018) menyebutkan bahwa dampak pengembangan pariwisata telah mampu menciptakan kesempatan kerja bagi masyarakat melalui terbukanya berbagai jenis usaha yang terkait dengan kepariwisataan dapat dimanfaatkan oleh para tenagakerja. Munculnya kesempatan kerja tersebut menyebabkan tenagakerja semakin tertarik untuk terjun ke dunia pariwisata.

Ketertarikan tenagakerja dalam aktivitas pariwisata di desa harus disikapi secara bijak oleh stakeholder terkait. Perubahan mind-set masyarakat tentang keberadaan desa wisata juga merupakan tantangan guna mampu memotivasi dan menggerakkan masyarakat desa untuk berpartisipasi aktif dalam menentukan arah pengembangan desa wisata ke depan. Sejalan dengan adanya perubahan mind-set masyarakat tersebut dapat memudahkan pihak pengelola dalam memberdayakan masyarakat secara optimal dalam pengembangan pariwisata berbasis masyarakat di desa.

Dewi, dkk. (2013); Yulianie (2015) menyebutkan pengembangan pariwisata berbasis masyarakat harus menitikberatkan pada keseimbangan dan keharmonisan di antara sumber daya alam dan sumber daya manusia serta pengunjung atau wisatawan yang dijiwai dengan pemanfaatan kearifan-kearifan lokal sebagai daya tarik wisatanya, memelihara lingkungan tetap lestari, mengkonsumsi hasil pertanian masyarakat setempat serta mencintai budaya, adat istiadat masyarakat. Melalui pengembangan pariwisata berbasis masyarakat, diharapkan masyarakat lokal menjadi pelaku penting dalam pengembangan desa wisata sehingga mereka merasakan implikasi positif dari pengembangan desa wisata.

Implikasi dari implementasi pengembangan pariwisata berbasis masyarakat di desa wisata Bongan dapat ditinjau dari konsep community-based tourism (CBT) yang dikemukakan oleh Suansri (2003). Merujuk konsep CBT Suansri tersebut implikasi pengembangan pariwisata dibedakan menjadi lima dimensi, yaitu: dimensi ekonomi, sosial, budaya, lingkungan, dan dimensi politik. Berikut dijelaskan indikator dari masing-masing dimensi. Dimensi ekonomi dengan indikator berupa adanya dana untuk pengembangan komunitas, terciptanya lapangan pekerjaan, timbulnya pendapatan masyarakat lokal dari sektor pariwisata. Dimensi sosial dengan indikator meningkatnya kualitas hidup, 
peningkatan kebanggaan komunitas, pembagian peran yang adil antara laki-laki dan perempuan, generasi muda dan tua, membangun penguatan organisasi komunitas. Dimensi budaya dengan indikator berupa mendorong masyarakat untuk menghormati budaya yang berbeda, membantu berkembangnya pertukaran budaya, budaya pembangunan melekat erat dalam budaya lokal. Dimensi lingkungan dengan indikator mempelajari carrying capacity, mengatur pembuangan sampah, meningkatkan kepedulian akan perlunya konservasi. Dimensi politik dengan indikator meningkatnya partisipasi dari penduduk lokal, peningkatan kekuasaan komunitas yang lebih luas, menjamin hak-hak dalam pengelolaan sumber daya alam.

Berdasarkan uraian di atas kelima dimensi community-based tourism tersebut dapat dipergunakan untuk menganalisis implikasi pengembangan pariwisata di desa wisata Bongan. Untuk itu artikel ini fokus mengkaji bagaimana implikasi pengembangan pariwisata bagi kehidupan masyarakat lokal di desa wisata Bongan baik ditinjau dari dimensi ekonomi, sosial, budaya, lingkungan, maupun dimensi politik.

\section{METODE PENELITIAN}

Artikel ini menggunakan data kualitatif. Pengumpulan data melalui metode observasi, wawancara, dan studi pustaka. Data informasi tentang implikasi ekonomi, sosial, budaya, lingkungan, dan politik bagi kehidupan masyarakat diperoleh dari tokoh masyarakat yang memahami tentang hal tersebut. Jumlah informan tidak ditentukan secara pasti. Penentuan informan dilakukan secara snowball sampling. Informan pertama diambil dari tokoh masyarakat (Kepada Desa), selanjutnya dilakukan pencarian informan lain atas petunjuk dari informan pertama, demikian seterusnya. Ketika jawaban sudah jenuh pengumpulan data dihentikan. Data dianalisis secara deskriptif kualitatif, melalui pengolahan dan penafsiran data yang merupakan rangkaian kegiatan penelahaan, pengelompokan, sistematisasi, penafsiran dan reifikasi data agar sebuah fenomena memiliki nilai sosial, akademis dan nilai ilmiah (Bungin, 2011: 45).

\section{HASIL DAN PEMBAHASAN}

Disadari bahwa dalam pengembangan pariwisata sangat komplek karena dalam pengembangannya melibatkan seluruh stakeholder terkait. Pelibatan stakeholder secara terintegrasi dapat memperlancar proses pengembangan desa wisata sehingga bisa berkelanjutan dan dapat dinikmati oleh generasi yang akan datang. Terkait dengan hal tersebut, Alavalapati dan Adamowicz (2000) menyebutkan bahwa dalam pengembangan destinasi wisata perlu membangun keseimbangan antara manfaat ekonomi dengan lingkungan secara nyata dan memberdayakan masyarakat lokal secara maksimal agar mampu menumbuhkan kesadaran dan tanggungjawab tinggi dalam pengembangan destinasi wisata. Gelbman and Timothy (2011) menyatakan bahwa elemen lingkungan pisik, sosial, dan budaya perlu mendapat perhatian serius dalam pengembangan pariwisata agar bisa berkelanjutan. Selanjutnya Nunkoo et al. (2012) menyebutkan bahwa masalah ekonomi, sikap pemerintah setempat, serta pandangan masyarakat lokal merupakan hal penting yang harus diperhatikan dalam pengembangan pariwisata berbasis masyarakat. 
Pariwisata berbasis masyarakat merupakan bentuk kepariwisataan dimana masyarakat lokal memiliki kontrol dan keterlibatan dalam pembangunan dan pengelolaannya secara substansial dan proporsi manfaat sebagian besar tetap berada di tangan masyarakat (Putra, 2015). Hal ini dapat dipakai sebagai acuan dalam mengimplementasikan pengembangan pariwisata di desa Bongan sehingga masyarakat mendukung pengembangan pariwisata mengingat mereka mendapat implikasi positif bagi kehidupannya.

Implikasi tentang pengembangan desa Bongan bagi kehidupan masyarakat lokal dianalisis dari beberapa pendapat dari tokoh masyarakat lokal. Tokoh masyarakat Bongan I Wayan Sukarta (Kepala Desa Bongan) dalam wawancara yang dilaksanakan di Kantor Desa Bongan, pada tanggal 15/03/2019 menyebutkan bahwa implikasi dari pengembangan desa wisata Bongan yaitu dalam pengelolaan desa wisata telah memerdayakan tenagakerja dari masyarakat desa yang diambil dari masing-masing banjar di desa Bongan. Secara eksplisit disebutkan bahwa tujuannya adalah untuk meningkatkan ekonomi serta dukungan masyarakat atas keberlanjutan dari pengembangan desa wisata. Dipahami bahwa dengan melibatkan masyarakat secara selektif dapat menumbuhkan kesadaran mereka untuk melestarian budaya yang dimiliki (kesenian baleganjur, tari Legong Keraton) guna mampu menarik minat kunjungan wisatawan. Hal serupa diungkapkan dalam penelitian Yudasuara (2015); Oka, dkk. (2019); Winia, dkk. (2019) yang menyatakan bahwa pengembangan desa wisata dapat berimplikasi positif terhadap kehidupan ekonomi maupun sosial budaya masyarakat lokal di desa wisata.

Selanjutnya dikatakan bahwa kontribusi stakeholder terkait baik pemerintah, akademisi, maupun pelaku pariwisata sangat dibutuhkan dalam mendorong pengembangan desa wisata. Kontribusi tersebut dapat berupa penyuluhan, pendidikan, dana, maupun mempromosikan keberadaan desa wisata kepada calon konsumen. Bila memungkinkan mendorong wisatawan untuk datang menikmati keindahan desa wisata Bongan. Disebutkan pula masyarakat khususnya aparat desa sudah mulai terlibat dalam kegiatan gotong-royong membersihkan lingkungan desa yang dilaksanakan seminggu sekali dengan harapan agar lingkungan selalu bersih dan terjadi komunikasi efektif antar wargag masyarakat.

Informan I Wayan Nadi (Sekdes Bongan) dalam wawancara yang dilakukan di Kantor Desa Bongan pada tanggal 29/03/2019 menyebutkan bahwa "implikasi penetapan desa menjadi desa wisata, yaitu mampu menumbuhkan ekonomi lokal artinya terjadi pembagian sistem bagi hasil secara adil untuk masyarakat yang terlibat dalam pengelolaan desa wisata, pengembangan desa wisata mampu meningkatkan pergerakan masyarakat dalam kegiatan kebersihan lingkungan, mampu membuat membuat masyarakat sejahtera melalui melalui program kesehatan, melestarikan seni dan potensi budaya yang dimiliki hingga saat ini, melibatkan anak-anak muda dalam festival budaya, memberi kesempatan kepada masyarakat lokal untuk memberikan masukan dalam pengelolaan desa wisata".

Pandangan informan ini menunjukkan bahwa sudah terlihat secara jelas adanya dukungan dari masyarakat dalam pengembangan desa wisata. Hal ini ditunjukkan dengan meningkatnya pergerakan masyarakat dalam menjaga kebersihan lingkungan. Namun pihak pengelola berharap ada dukungan dari akademisi terutama dalam memberikan sosialisasi tentang kemanfaatan dari pengembangan desa wisata baik dalam pengelolaan, pengemasan paket wisata, 
maupun kemungkinan munculnya dampak positif maupun dampak negatif dari pengembangan desa wisata. Keterbukaan pihak pengelola juga terlihat dari adanya pemberian kepada masyarakat umum untuk memberikan masukan dan saran demi kemajuan dari perkembangan desa wisata. Penetapan desa Bongan menjadi desa wisata bertujuan untuk melestarikan seni dan potensi budaya yang dimiliki hingga saat ini sehingga generasi muda dilibatkan dalam kegiatan festival budaya. Hal serupa juga terungkap dalam penelitian Oka, dkk. (2018) yang dikatakan bahwa dalam pengembangan desa wisata mampu menumbuhkan kesadaran masyarakat dalam melestarikan budaya.

Informan I Nyoman Surata (Bendesa Adat Desa Pakraman Bedha) dalam wawancara di lokasi Situs Kebo Iwa pada tanggal 22/04/2019, menyebutkan bahwa implikasi dari pengembangan desa wisata yaitu mampu menumbuhkan kesadaran masyarakat dalam melestarikan budaya yang dimiliki, seperti Situs Kebo Iwa, upacara Ngaben Bikul, dan parade budaya. Situs Kebo Iwo dijadikan sebagai ikon dalam pengembangan desa wisata. Parade budaya dilaksanakan setiap tahun mulai tahun 2016. Kegiatan parade budaya dilaksanakan setiap bulan Agustus sekaligus dikaitkan dengan perayaan Hari Kemerdekaan Negara Republik Indonesia. Dalam kegiatan parade budaya ditampilkan baleganjur dengan tema "Nangluk Merane". Kegiatan parade budaya yang diselenggarakan dengan melibatkan para sekeha baleganjur di masing-masing banjar yang terdapat di desa Adat Bedha. Selanjutnya disebutkan pula terdapat potensi pariwisata baru untuk dikembangkan di desa ini yaitu keberadaan air terjun Grembengan yang dapat dijadikan sebagai wisata spiritual.

Kini untuk lebih memperkenalkan atraksi pariwisata di desa Bongan pihak pengelola desa wisata mengharapkan bantuan dari pihak pelaku pariwisata dan akademisi untuk mempromosikan atraksi pariwisata yang dimiliki calon konsumen sehingga gemanya menjadi lebih besar. Dalam mempromosikan keberadaan desa wisata Bongan perlu diciptakan image yang menjadi brand desa wisata. Melalui brand ini diharapkan mampu membuat desa wisata ini semakin dibicarakan di kancah dunia. Budiasih (2017) menyebut kemajuan perkembangan teknologi informasi (media sosial), seperti internet dan turunannya, seperti: facebook, twitter, email, blog, online, dan yang lainnya memiliki andil besar sebagai trigger atau pull factor, bagi wisatawan untuk melakukan perjalanan wisata ke destinasi pariwisata. Oleh karenanya media social dapat dimanfaatkan untuk mempromosikan keberadaan desa wisata Bongan.

Informan I Nengah Mangkir (Pengelola desa wisata) dalam wawancara tanggal 27/05/2019 menjelaskan bahwa "dengan ditetapkannya desa wisata Bongan sebagai desa wisata telah berimplikasi positif bagi kehidupan masyarakat seperti meningkatkan pendapatan masyarakat, meningkatkan partisipasi masyarakat dalam kegiatan pariwisata, menumbuhkan kesadaran masyarakat dalam membersihkan lingkungan, melestarikan seni dan potensi budaya. Namun disadari pula masih ada yang perlu dibenahi lagi agar desa wisata ini semakin berkembang dan mampu bersaing secara kompetitif".

Pandangan informan ini menunjukkan bahwa pengembangan desa wisata disadari mampu meningkatkan perekonomian masyarakat lokal karena masyarakat lokal yang diutamakan untuk direkrut menjadi tenagakerja di desa. Hal tersebut dipahami mampu memotivasi masyarakat untuk berkontribusi dalam pengembangan desa wisata. Kondisi ini menimbulkan motivasi dalam diri 
masyarakat untuk terus berkontribusi lebih dan ikut bertanggungjawab atas keberhasilan dari pengembangan desa wisata. Harapannya adalah keberlanjutan dari pengembangan desa wisata dapat direalisasikan sesuai program kerja sehingga mampu bersaing secara kompetitif dengan desa wisata lain yang sejenis khususnya di Kabupaten Tabanan. Pembenahan dan penyempurnaan program kerja harus tetap dilakukan demi kelancaran dari pengembangan desa wisata.

Pengunjung I Nyoman Sudiarta dalam wawancara pada tanggal 17/09/2019 menyatakan bahwa keberagaman atraksi yang dimiliki desa Bongan seperti situs Kebo Iwa, penangkaran burung jalak Bali hendaknya dirawat dan dikelola secara profesional sehingga tetap menjadi ciri khas utama bagi wisatawan untuk berkunjung. Pengelolaan fasilitas penunjang pariwisata seperti warung makan dan villa diharapkan terintegrasi dengan paket wisata yang dimiliki sehingga wisatawan dapat menginap sekaligus menikmati suasana kehidupan masyarakat desa. Pengunjung yang datang mengharapkan mendapat pengalaman edukasi ketika berekreasi atau berlibur. Disebut pula lokasi desa Bongan sangat strategis karena sering digunakan sebagai jalur menuju daya tarik wisata Pura Tanah Lot menjadikan desa wisata ini sering disinggahi oleh wisatawan. Lebih lanjut pengunjung lain I Nyoman Winia menyebutkan keberadaan situs Kebo Iwa perlu tetap dipertahankan dan dirawat dengan baik. Bila memungkinkan wisatawan yang datang disuguhi dengan sejarah situs tersebut yang telah dikemas secara apik dan menarik sehingga wisatawan lebih yakin terhadap keberadaan situs tersebut sebelum mereka melihat secara langsung.

Berdasarkan uraian tersebut di atas dapat dikemukakan implikasi pengembangan pariwisata berbasis masyarakat bagi kehidupan masyarakat lokal Bongan, dapat ditinjau dari lima dimensi, yaitu: dimensi ekonomi, sosial, budaya, lingkungan, dan dimensi politik.

1) Dimensi ekonomi. Pengelola desa wisata Bongan telah melibatkan masyarakat lokal sebagai tenagakerja pariwisata di desa. Masyarakat direkrut untuk bekerja pada usaha jasa penginapan villa, tenagakerja pariwisata, membuka warung makan serta menjadi anggota kelompok Kicau Bali yang merupakan kelompok penjual burung "Jalak Bali" kepada tamu yang berkunjung. Dengan demikian masyarakat mendapat manfaat ekonomi dari pengembangan pariwisata desa secara signifikan demi memenuhi kebutuhan diri dan keluarga.

2) Dimensi sosial. Masyarakat lokal terlibat secara aktif dalam pengembangan pariwisata sehingga mampu meningkatkan kualitas hidup mereka. Interaksi yang efektif terjadi antar warga masyarakat dalam kehidupan sehari-hari. Kontribusi peran masyarakat dalam pengembangan desa wisata sesuai dengan kemampuannya demi membangun desa tercinta.

3) Dimensi budaya. Desa Bongan memiliki visi untuk melestarikan seni dan budaya yang dimiliki agar seni dan budayanya tetap lestari dan berkelanjutan, seperti pelatihan tari dan tabuh bagi masyarakat. Di desa Bongan telah didirikan sanggar tari di banjar Bongan Kauh yang melibatkan anak-anak muda guna melestarikan tarian khas desa Bongan yaitu tari Legong Keraton. Visi desa wisata ini sangat mulia yaitu dapat mempertahankan sekaligus melestarikan budaya yang dimiliki sehingga bisa dinikmati oleh wisatawan maupun masyarakat setempat secara berkelanjutan.

4) Dimensi lingkungan. Desa Bongan telah mengikutsertakan masyarakat dalam kegiatan kebersihan lingkungan (kerja bakti) guna untuk menjaga dan merawat 
lingkungan karena desa yang bersih dan nyaman merupakan salah satu aspek penting dalam pengelolaan desa wisata. Mereka menyadari bahwa dengan menjaga kelestarian lingkungan dapat menarik wisatawan untuk berkunjung ke desa.

5) Dimensi politik, yaitu dalam pengelolaan desa wisata telah memprioritaskan masyarakat lokal sebagai tenagakerja, serta menjamin hak-hak mereka dalam pengelolaan desa wisata. Dengan demikian dapat dikemukakan bahwa desa Bongan sangat menginginkan adanya partisipasi aktif masyarakat dalam pengembangan desa wisata mengingat merekalah pemilik desa yang lebih memahami keberadaan desanya.

\section{PENUTUP}

Pengembangan pariwisata berbasis masyarakat di wisata desa Bongan mampu memberikan implikasi positif bagi kehidupan masyarakat lokal baik ditinjau dari dimensi ekonomi, sosial, budaya, lingkungan, maupun dimensi politik. Implikasi ekonomi tersebut dapat dilihat dari terjadinya peningkatan pendapatan masyarakat dengan adanya pengembangan pariwisata karena mereka terlibat secara aktif dalam kegiatan pariwisata, seperti menjadi karyawan di villa, rumah makan, dan kelompok kicau burung. Implikasi sosial, yaitu pengembangan pariwisata mampu meningkatkan kualitas hidup mereka mengingat terjadi interaksi yang efektif terjadi antar warga masyarakat dalam kehidupan sehari-hari, serta kontribusi peran yang mereka rasakan dalam pengembangan desa wisata telah sesuai kemampuan demi membangun desa tercinta. Implikasi budaya, yaitu dapat menumbuhkan kesadaran masyarakat dalam melestarikan dan menghormati tradisi budaya seperti adanya pembangunan sanggar seni dan tabuh. Implikasi lingkungan, yaitu mampu meningkatkan kesadaran dalam menjaga kebersihan lingkungan melalui gotong-royong. Implikasi politik, yaitu masyarakat diprioritaskan dalam perekrutan tenaga kerja. Dirasakannya manfaat dari pengembangan pariwisata tersebut mampu meningkatkan antusias mereka dalam mendukung pengembangan pariwisata di desa Bongan.

Untuk itu diharapkan seluruh stakeholder terkait ikut berperan aktif dalam mendukung pengembangan pariwisata di desa Bongan baik berupa motivasi, pembinaan, manajemen pengelolaan, maupun promosi demi keberlanjutannya di masa depan. Hal ini dilakukan demi keberlanjutan dari pengembangan desa wisata Bongan agar mampu bersaing secara kompetitif dengan wisata sejenis.

\section{DAFTAR PUSTAKA}

Alavalapati, J.R.R. dan Adamowicz. W.L. (2000). "Tourism Impact Modelling for Resource Extaction Regions", Annals of Tourism Research, 27 (1), 188202.

Budiasih, M. (2017), Pariwisata Spiritual di Bali, Jurnal Ilmiah Agama dan Budaya, Vol. 2 (1). P. 70-80. Diunduh 15 Maret 2020, dari https://www.researchgate.net/publication/335763433

Bungin, B. (2011). Metode Penelitian Kualitatif. Aktualisasi Metodologis ke Arah Ragam Varian Kontemporer. PT. Raja Grafindo Persada. Jakarta

Dewi, M. Urmila. (2013). Pengembangan Desa Wisata Berbasis Partisipasi Masyarakat Lokal Di Desa Wisata Jatiluwih Tabanan, Bali. Kawistara. Vol 3 No 2: Hal 117-226. 
Gelbman, A., and Timothy, D.J. (2011). "Border Complexity, Tourism and International Exclaves; A Case Study", Annals of Tourism Research, 38 (1), 110-131.

Nunkoo, R., H. Ramkissoon, and D. Gursoy. 2012. "Public Trust in Tourism Institutions", Annals of Tourism Research, 39 (3), 1538-1564

Oka, I. M. D., Winia, I. N., \& Sadia, I. K. (2019, November). The Implication of the Development of Serangan Tourist Village from the Economic Perspective. In International Conference on Social Science 2019 (ICSS 2019). Atlantis Press. Diunduh tanggal 4 Maret 2020 dari https://www.atlantis-press.com/proceeding /icss-19/125923531

Oka, I. M. D., Winia, I. N., \& Sadia, I. K. (2018). The Motivation of Serangan Community to Support the Development of Tourism at Serangan Village. In 1st International Conference on Social Sciences (ICSS 2018). Atlantis Press. Diunduh dari https://www.atlantis-press. com/proceedings/icss$18 / 25903861$

Oka, I. M. D., \& Sumawidari, I. A. K. (2018). The Factors that Motivate Balinese Women Working on Cruise Ships. International Journal of Applied Sciences in Tourism and Events, 2(2), 125-134. Diunduh tanggal 12 Peb 2010 dari http://ojs.pnb.ac.id/index.php/IJASTE/article/view/1178

Oka, I. M. D., Winia, I. N., \& Pugra, I. W. (2017). Pemberdayaan Masyarakat Melalui Pelatihan Pengolahan Masakan Seafoods untuk Menunjang Pariwisata di Desa Wisata Serangan. Bhakti Persada Jurnal Aplikasi IPTEKS, 1(1), 62. Diunduh dari http://ojs.pnb.ac.id/index.php/BP/article/ view/250

Oka, I.M.D; Sumawidari, I.A.K. (2017). "Image Daya Tarik Wisata Alas Kedaton di Desa Kukuh, Marga, Tabanan”, Soshum: Jurnal Sosial dan Humaniora, 3 (2 Juli), p. 202. Dari <http://ojs.pnb.ac.id/index. php/ SOSHUM/article/view/597>.

Oka, I. M. D., \& Made, I. (2015). Perempuan Bali Dalam Industri Pariwisata Kapal Pesiar. Disertasi, Denpasar: Universitas Udayana.

Patriani, N. K. T., Mataram, I. G. A. B., Oka, I. M. D., \& Sadia, I. K. (2018). Analysis of Receptionist Service Quality for the Tourist's Satisfaction at the Grand Inna Hotel Kuta. Journal of Applied Sciences in Travel and Hospitality, 1(3), 228.

Pantiyasa, 2019, Model Pengembangan Desa Wisata Denpasar, STPBI PRESS

Pantiyasa, 2019, Konstruksi Model Pengembangan Desa Wisata Menuju Smart Eco Tourism di Desa Paksebali , Jurnal Kajian Bali Vol 9 No. 01

Putra, I.N.D. (2015). Pariwisata Berbasis Masyarakat Model Bali. Universitas Udayana. Denpasar.

Sadia, I. K., \& Oka, I. M. D. (2012). Motivasi Tenaga Kerja Bali Bekerja di Mediterranean Shipping Company (MSC). Jurnal Sosial Humaniora, Vol. 2 (3), 221-236. Diunduh 25 Maret 2020 dari https://scholar.google.com/scholar?cluster=9534431460458001299\&hl

Winia, I. N., Oka, I. M. D., \& Pugra, I. W. (2019, October). The Implementation of the Community-based Tourism at Tista Tourist Village. In International Conference on Applied Science and Technology 2019-Social Sciences Track (iCASTSS 2019). Atlantis Press. Diunduh dari https://www.atlantispress.com/procee dings/icastss-19/125920858. 
Yudasuara, I K. (2015). Pengelolaan Daya Tarik Wisata Berbasis Masyarakat di Desa Pecatu. Pariwisata Berbasis Masyarakat Model Bali. PS. Magister Kajian Pariwisata Universitas Udayana. Denpasar.

Yulianie, F. 2015. Partisipasi Dan Pemberdayaan Masyarakat Dalam Pengelolaan Daya Tarik Wisata "Rice Terrace" Ceking, Gianyar, Bali. Jurnal Master Pariwisata (JUMPA). Vol 2 No 1, hal 165-184 